\title{
Von Zumbusch's Pustular psoriasis treated with an unction containing honey and green propolis coming from certain regions of Brazil
}

\author{
Piotr Brzeziński', Lorenzo Martini ${ }^{1,2}$, César Bimbi ${ }^{3}$
}

${ }^{1}$ University of Siena, Department of Pharmaceutical Biotechnologies, Via A. Moro 2, 53100 Siena, Italy, ${ }^{2}$ C.R.I.S.M.A. Inter

University Centre for Researched Advanced Medical Systems, ${ }^{3}$ Dermatology Centro Historico Porto Alegre, Brazil

Corresponding author: Prof. Lorenzo Martini, E-mail: martini36@unisi.it

\begin{abstract}
Pustular psoriasis, especially the Von Zumbusch's one, is one of the most difficult psoriasis to be cured both at home and at hospital. Many are the suggestions to treat or prevent it, even nutraceuticals, sun rays and/or special antibiotics. One of the AA who drafted this paper had developed this syndrome and declared to colleagues to be always tired, nervy, to feel legs swelling and suffer from tachycardia (he supposed that this symptom was caused from hypocalcemia) and black urination. So he made up his mind to test on himself (in corpore vili) the ointment the AA had ideated, keeping on account that this unction contains a special green propolis and honey coming from Brazil. Results are very satisfactory. Only one week to behold a complete remission of the PP.
\end{abstract}

Key words: Von Zumbusch’ PP; Yellow beeswax; Liver cod oil; Vit. F; Hypocalcemia; Tachycardia

\section{INTRODUCTION}

Pustular psoriasis is a severe but not contagious skin disease.

The chief manifestations are represented by white bumps filled with pus near or inside red skin blotches. These are called pustules, and they can hurt and be scaly, flaky, or itchy.

It's most likely to affect the palms of hands, the soles of feet, fingers and toes.

Even though one may observe pus on the bumps, it's not an infection. One can't catch pustular psoriasis from someone else or give it to others $[1,2]$.

Pustular psoriasis usually happens to adults - it's rare for kids to have it. It can run in families.

Some people experience cyclic periods of pustules and remission. While the pus is noninfectious, this condition can cause flu-like symptoms such as: fever; chills; rapid pulse; muscle weakness; loss of appetite.

There are three kinds of pustular psoriasis: von Zumbusch; palmoplantar pustulosis (PPP); acropustulosis.

Each of the three forms of pustular psoriasis can have different symptoms and severity.

Treatment for pustular psoriasis depends on the size of the affected area. Smaller patches are often treated with corticosteroid creams, either OTC or prescription. Larger patches may need treatment with oral medications and light therapy $[3,4]$.

Identifying and treating the underlying cause may also help reduce reoccurrence of pustular psoriasis.

Von Zumbusch can develop at any age but predominately affects adults over 50. The outbreak of symptoms, referred to as a flare, may be triggered by any number

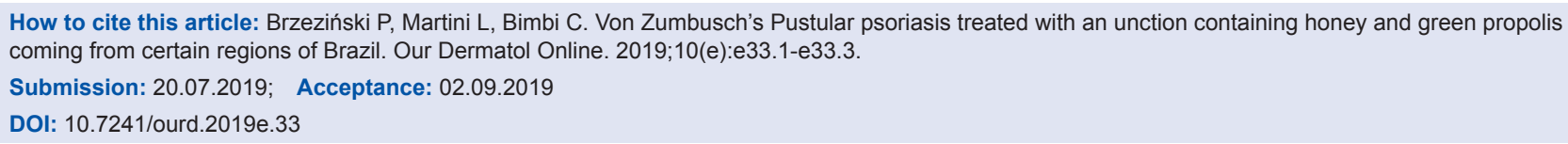


of things, including medications and stress. Diagnosed by a physical exam and the evaluation of a pus sample, Von Zumbusch almost always requires treatment in a hospital $[5,6]$.

Von Zumbusch can appear abruptly on the skin. The symptoms start with widespread areas of reddened skin that become increasingly painful and tender. Within hours, tiny pustules will appear, many of which will consolidate into larger blisters. The pustules can easily rupture when scratched or abraded. Fever and fatigue are common [7].

Within 24 to 48 hours, the pustules will dry up, leaving a glazed and smooth appearance. The affected skin can be extremely itchy and peel away in sheets. This is not only painful but can lead to the rapid loss of moisture and massive dehydration.

Symptoms of severe dehydration can include: Extreme thirst; Dry mouth; Headaches; Reduced urination; Dark-colored urine; Fatigue; Sleepiness; Dizziness; Confusion; Muscle weakness; Rapid heart rate; Rapid, shallow breathing; Fever and chills; Leg swelling.

With Von Zumbusch psoriasis, there are certain specific triggers known to incite a flare $[8,9]$.

Emotional stress; The abrupt discontinuation of corticosteroid drugs; Medications, including salicylates, lithium, penicillin, interferon, and terbinafine; Strong, irritating topical medications, such as coal tar or anthralin; Skin infections, especially Staphylococcus aureus and Streptococcus epidermidis; Excessive sun exposure; Phototherapy; Hypocalcemia (low blood calcium); Pregnancy, most especially during the third trimester; Bacille CalmetteGuerin (BCG) vaccination for tuberculosis.

Despite the plethora of common triggers, most cases of pustular psoriasis are idiopathic, meaning of no known cause.

Supportive therapy with cool compresses and saline or oatmeal baths can help soothe the skin and gently remove (debride) dead skin.

To help temper the acute flare, an oral retinoid called Soriatane (acitretin)is commonly prescribed. Retinoids slow the hyperproduction of skin cells and help bring the acute symptoms under control. Severe cases may require immunosuppressant drugs like methotrexate or cyclosporine of the biologic drug Remicade (infliximab) [10,11].

One the acute crisis has passed, a type of phototherapy, known as psoralen and ultraviolet A (PUVA), may be used to bring the condition into sustained remission.

There is really no way to prevent Von Zumbusch psoriasis given that we know so little about the underlying causes. With that being said, if you have had a previous flare, you are at risk of recurrence and need to take preventive action. This should include:

Avoiding known triggers; Stopping smoking; Reducing your alcohol intake; Avoiding excessive sun exposure; Managing emotive stress.

\section{MATERIALS AND METHODS}

The AA have ideated a salve (a natural balsam) that has demonstrated suggestive results.

Only one of the AA has experimented on himself the ointment, on his own elbows affected by P.P. and the remission is complete after $5-7$ days.

He is always emotively stressed, drinks wine and smokes too much. Recently he felt fatigue and legs swelling and suffered from tachycardia and black urination.

The cosmetic formula is the following: Yellow beeswax; Propolis cera; Lanolin; Cod liver oil (because it is rich in vit. F); Jamun honey; Green Propolis extract.

It is interesting to stress that the cosmetic system presents a melting point at $26.4^{\circ} \mathrm{R} \varnothing\left(98.6^{\circ} \mathrm{F}\right.$ or $\left.36^{\circ} \mathrm{C}\right)$ corresponding to the human skin temperature and likewise vit. F of the cod liver oil is exceptional for the cure of all types of psoriasis too.

Green propolis is native to the the State of Minas Gerais (Brazil) also known as Rosemary Bush or Buckwheat.

Beyond the traditional nutrients present in propolis that propolis also offers the Artepelin substance C, with antibiotic properties, anti-inflammatory and wound healing.

Jamun (Syzygium cumini) honey is famous for its antihypoxic activity. A specific dose of this honey can be topically applied to cure the deadly Fournier gangrene. 
Since it has high osmotic pressure and viscosity, it prevents microbial growth and promotes wound healing when applied to the affected areas $[12,13]$.

One of the AA used to spread generously the ointment on his elbows in the morning and in the night, before to go to sleep for an entire week.

\section{RESULTS}

The experimenter has had the chance to behold these cutaneous manifestations during the weekly treatment:

- After the first day the injured skin was completely red and lucid

- After the second day he did not feel anymore itch

- After the third day the real remission began and between $5^{\text {th }}$ and $7^{\text {th }}$ day flares disappeared at all.

\section{CONCLUSIONS}

The experimenter has used for 4 days after the treatment a vanishing emulsion containing allantoin to maintain the skin soft and matt.

The results are encouraging.

Even the symptoms (nausea, fever, leg swelling and rapid heart rate) have been disminishing day after day.

At $8^{\text {th }}$ and $9^{\text {th }}$ day urine was clear.

\section{Statement of Human and Animal Rights}

All procedures followed were in accordance with the ethical standards of the responsible committee on human experimentation (institutional and national) and with the Helsinki Declaration of 1975, as revised in 2008.

\section{Statement of Informed Consent}

Informed consent was obtained from all patients for being included in the study.

\section{REFERENCES}

1. Twelves S, Mostafa A, Dand N, Burri E, Farkas K, Wilson R, et al. Clinical and genetic differences between pustular psoriasis subtypes. J Allergy Clin Immunol. 2019;143:1021-6.

2. Lai CSE, Mohammad MN, Norshaleyna A, Nalini M, Tey KE, Fern CS. Clinical profile, morbidity, and outcome of adult-onset generalized pustular psoriasis: analysis of 102 cases seen in a tertiary hospital in Johor, Malaysia. Int J Dermatol. 2014;53:676-84.

3. Vijayashankar M, Raghunath N. Pustular psoriasis responding to Probiotics - a new insight. Our Dermatol Online. 2012; 3:326-8.

4. Ndiaye M, Ly F, Dioussé P, Diallo M, Diop A, Diatta BA, et al. [The characteristics of severe forms of psoriasis on pigmented skins: A retrospective study of 102 cases in Dakar, Senagal]. Our Dermatol Online. 2017;8:138-42.

5. Gusmão Guerreiro de Moura CA, Henrique de Assis L, Góes P, Rosa F, Nunes F, Sampaio Cruz CM. A case of acute generalized pustular psoriasis of von Zumbusch triggered by hypocalcemia. Case Rep Dermatol. 2015;7:345-51.

6. Robinson A, Van Voorhees AS, Hsu SN, Neil J, Lebwohl MG, Bebo BF, et al. Treatment of pustular psoriasis: from the Medical Board of the National Psoriasis Foundation. J Am Acad Dermatol. 2012;67:279-88.

7. Puri N, Mahajan BB. A study of clinical and biochemical correlation in patients of psoriasis in acute exacerbation. Our Dermatol Online. 2014;5:135-9.

8. Wang Q, Liu W, Zhang L. Clinical features of von Zumbusch type of generalized pustular psoriasis in children: a retrospective study of 26 patients in southwestern China. An Bras Dermatol. 2017;92:319-22.

9. Owczarczyk-Saczonek A, Znajewska-Pander A, Owczarek W, Maciejewska-Radomska A, Placek W. Clinicopathologic retrospective analysis of annular pustular psoriasis. Acta Dermatovenerol Alp Pannonica Adriat. 2018;27:215-9.

10. Niculet E, Tatu AL, Lupasteanu G, Vicol C. Innovations in psoriasis treatment with curcuma longa. RoJCED 2018;5:106-9.

11. Abhinav C, Mahajan VK, Mehta KS, Chauhan PS, Gupta M, Rawat M. Weekly methotrexate versus daily isotretinoin to treat moderateto-severe chronic plaque psoriasis: a comparative study. Our Dermatol Online. 2015;6:392-8.

12. Varman KM, Namias N, Schulman CI, Pizano LR. Acute generalized pustular psoriasis, von Zumbusch type, treated in the burn unit. A review of clinical features and new therapeutics. Burns. 2014;40:e35-9.

13. Griffiths C, Barker J, Bleiker T, Chalmers R, Creamer D. Rook's textbook of dermatology. John Wiley \& Sons. 2016.

Copyright by Piotr Brzeziński, et al. This is an open-access article distributed under the terms of the Creative Commons Attribution License, which permits unrestricted use, distribution, and reproduction in any medium, provided the original author and source are credited. Source of Support: Nil, Conflict of Interest: None declared. 